\title{
La Emergencia de la Idea de Nacionalidad en el México Colonial
}

A idea o conciencia de nacionalidad en un grupo étnico o geográfico es el resultado de un complejo de factores sociales, culturales y geográficos que, desarrollándose a lo largo de un periodo más o menos largo, llega a establecerse en la conciencia de ese pueblo y hace que éste se manifiste como una entidad social y culturalmente distinta de todas las otras.

En este breve estudio me propongo examinar las manifestaciones de esta idea de nacionalidad en el México colonial, su gradual formación y la aparición definitiva de una conciencia de mexicanidad, es decir, de nacionalidad mexicana, distinta y separada de la española. No es mi propósito entrár en el examen de los caracteres precisos que identifican esta nacionalidad, ni tampoco analizar los escritos de todos los autores importantes de la época colonial. Solamente me limitaré, dentro de la brevedad del tiempo aquí disponible, y examinando el testimonio de algunos de los escritores más salientes, a responder a estas preguntas: ¿Cuándo surge en México la idea de nacionalidad mexicana, distinta de la española? ¿Cuándo se consideran los mexicanos un grupo social y cultural de personalidad propia?. ¿Vino esta conciencia de la nacionalidad mexicana con la lucha por la independencia o quedó ya establecida con los conquistadores y sus descendientes en el siglo XVI?

Antes de responder a estas preguntas recordemos que la nacionalidad mexicana tal como la conocemos hoy es el producto de la unión de dos razas y de dos culturas: la española y la mexicana. Bien ha dicho Agustín Yáñez: 1 "La mexicanidad, como fisonomía cultural vigente, nace del recio ayuntamiento de fuerzas entre sí 
extrañas, que fué la conquista. Ni esa fisonomía es, como algunos quieren, la arcaica forma de las culturas autóctonas, ni tampoco, según la pasión de otros, 10 español absoluto que ahoga y suplanta categóricamente -absurdo histórico- cuanto los siglos edificaron en el alma y la tierra aborígenes. No era posible tamaño arrasamiento ni España se lo propuso."

Durante el transcurso de tres siglos, por lo menos, estas dos razas y estas dos culturas se compenetran y se influyen mutuamente. De esta compenetración e influencia mutuas emerge al fin en el siglo XIX la nación mexicana, que no es ya española ni es india tampoco, sino algo que se eleva sobre las dos, habiendo heredado de ella caracteres inconfundibles.

Desde aquel día memorable en que los caciques de Tlaxcala ofrecen sus hijas a Cortés y a sus capitanes, para obtener de ellos progenie tan invencible como la raza española, queda establecido el principio de la nueva raza mexicana. Los españoles por su parte aceptan a las nobles hijas de Tlaxcala, y más tarde a las de México, como compañeras sobre una base de igualdad, tal vez algo extraña en conquistadores que, como los españoles del siglo XVI, se consideraban superiores a los de cualquiera otra nación. Si es verdad que al principio rara vez consagraban su unión con el matrimonio, hay que tener en cuenta que, como dice Madariaga, 2 "el matrimonio en el sentido cristiano de la palabra era desde luego cosa superflua para los tlaxcaltecas y la deferencia que los capitanes españoles manifestaron para con sus concubinas indias, a las que trataron como iguales e hicieron servir como señoras, no sólo por sus criados indios sino también por sus criados españoles, cimentó una amistad ya establecida sobre bases sólidas por la mutua estima nacida en el campo de batalla". Estas nobles mexicanas eran para los españoles esposas en todo, menos en el sacramento. Les daban el título de doña, símbolo de nobleza. De este modo vemos siempre mencionada por los cronistas a la famosa doña Marina, a la que Cortés hizo madre de uno de sus hijos, don Martín Cortés, Comendador más tarde de la Orden de Santiago; a doña Luisa, hija de Xicoténcatl, cacique principal de Tlaxcala, de la cual nos dice Bernal Díaz del Castillo 3 que "ansí como se la dieron (a Alvarado) toda la mayor parte de Tlaxcala la acataban y le daban presentes y la tenían por señora y della hobo el Pedro de Alvarado siendo soltero un hijo que se dijo D. Pedro e una hija que se dice Doña Leonor, 
muger que agora es de D. Francisco de la Cueva, buen caballero, primo del Duque de Albuquerque". Estos casos se repiten y aumentan según va avanzando la conquista. El mestizo, el nuevo mexicano, el germen de la nueva nacionalidad, aparece entonces en escena.

En cuanto a los conquistadores, debemos también recordar que todos ellos, empezando por Cortés, terminan siendo conquistados por México, y establecen sus hogares en esta su nueva patria, la Nueva España. A ella dedican sus afanes y su cariño. Si vuelven a España se sienten allí extraños y casi extranjeros. Su corazón está en México. México los ha conquistado y a México vuelven, o mandan, como Cortés, ser enterrados en su nueva patria, la nueva nación con cuya grandeza sueñan y cuyos fundamentos asentaron. Sabiamente se había preocupado Cortés por la futura prosperidad y ajustamiento económico-social entre las dos razas, cuando en su cuarta Carta al Emperador Carlos V escribió : 4

"Como a mí me convenga buscar toda buena orden que sea posible para que estas tierras se pueblen y los españoles pobladores y los naturales de ellas se conserven y se perpetúen y nuestra santa fe en todo se arraigute... hice ciertas Ordenanzas y las mandé pregonar. De algunas de ellas, los españoles que en estas partes residen no están muy satisfechos, en especial de aquellas que los obligan a arraigarse en la tierra porque todos o los más tienen pensamientos de se haber con estas tierras como se han habido con las Islas que antes se poblaron que es esquilmarlas y destruirlas y después dejarlas y porque me parece que sería muy gran culpa de los que de lo pasado tenemos experiencia no remediar lo presente y porvenir, proveyendo en aquellas cosas por donde nos es notorio haberse perdido las dichas Islas, mayormente siendo esta tierra, como yo muchas veces a $V$. M. he escrito, de tanta grandeza y nobleza y donde tanto Dios Nuestro Señor puede ser servido."

En estas palabras memorables vemos retratados el efecto y la admiración de Cortés hacia la tierra de su adopción: "tierra de tanta grandeza y nobleza" - grandeza y nobleza que él quiere perpetuar.

Otro elemento hay que tener en cuenta en la formación de la nueva nacionalidad mexicana: el misionero, el conquistador espiritual que a la vez que convierte al indio y le gana para la religión católica, es conquistado él mismo por la nueva tierra y sus habitantes. A ellos consagra toda su vida y en su defensa y protección esgrime 
sus armas espirituales y su pluma contra los abusos de los españoles. Tipo supremo del misionero que funde su alma con el alma indígena es el P. Bartolomé de las Casas, a quien uno de sus modernos biógrafos, Agustín Yảñez, llama el buen americano. En las páginas de su Apologética Historia vemos bien delineados los fundamentos de la nueva americanidad. Como dice Yáñez: 5 "Para Colón, como para Cortés y para Díaz del Castillo, el Nuevo Mundo es una sorpresa, un espectáculo presente y materia que transformar; en cambio para Las Casas es objeto de inflamado amor; nadie antes que Fray Bartolomé despliega y consigue tan fecunda postura de comprensión; entre los fundadores resulta el más cabal americano: su celo descubre los valores antiguos que no es posible desechar, sino forzosamente aceptar como cimientos del nuevo edificio; las culturas aborígenes, más que fenómenos curiosos, en punto de abolición, aparecen como elementos dignos de incorporarse al imperio cristiano."

Esta veneración y respeto a lo autóctono mexicano no son exclusivos de Las Casas. Indirectamente los encontramos ya en las Cartas de Relación de Cortés y en la Crónica de Bernal Díaz, y en las Historias de Motolinia y de Fr. Bernardino de Sahagún, a los que debemos la mayor parte de nuestros conocimientos sobre las culturas precortesianas. Pero hay otro misionero que, tanto o más que Las Casas, ciertamente con menos estrépito, se identifica con el México primitivo, lo estudia, lo comprende, y dedica la labor de toda su vida a su bienestar social y espiritual: don Vasco de Quiroga, primer obispo y apóstol de Michoacán, quien en su Información en Derecho nos habla con fervorosa admiración de la "edad dorada" del indígena "...que ya es vuelta entre nosotros de hierro y de acero y peor." Esta Información es una defensa de las dotes y excelentes cualidades de mexicano primitivo, tan cálida y ferviente como to mejor que salió de la pluma del infatigable Las Casas. Admira la paciencia del indio, su humildad, su fragilidad, su "buena simplicidad y voluntad", sus fiestas que son "por sus grandes areitos, cantares, bailares, y juegos del palo y de los voladores... cosa cierta mucho de ver"... "y que a quienquiera parecerá heroica y de mucha majestad". 6 Don Vasco de Quiroga no sólo defiende las dotes del mexicano y proclama sus virtudes, sino que también los propone como ejemplos de imitación a los mismos españoles. Vemos aquí el alma indígena infiltrándose en la española. La influencia 
es mutua. Dice don Vasco: "Aquestos naturales nos vémoslos todos naturalmente dados e inclinados a todas estas cosas que son fundamento y propias de nuestra fe y religión cristiana, que son humildad, paciencia y obediencia y descuido y menosprecio de estas pompas, faustos de nuestro mundo y de otras pasiones del ánima, y tan despojados de todo ello, que parece que no les falta sino la fe, para ser perfectos y verdaderos cristianos; $y$ por todo esto no sin mucha causa éste se llama Nuevo Mundo, porque así como estos naturales de él, aún se están... en la edad dorada de él, así ya nosotros habemos venido decayendo de ella y de su simplicidad y buena voluntad y venido a parar en esta edad de hierro." 7

Cuánto dista el obispo de Michoacán de aquel escolástico renacentista, Juan Ginés de Sepúlveda, quien en su sabia ignorancia proponía, contra Las Casas, la inferior condición racional del indio como causa justificante de su subyugación.

Vemos, pues, cómo no muchos años después de la conquista aparecen en gran número los primeros símbolos de la nueva nacionalidad en México: el español conquistado por el ambiente y por la tierra, sus hijos, los criollos y los mestizos, los indios convertidos a una nueva religión y a una nueva cultura, y el misionero que con ellos se identifica. Concomitante a estos factores, o quizás efecto de ellos, es el interés que muestran casi todos los escritores del siglo XVI en México por las tradiciones, leyendas y costumbres de los antiguos pueblos mexicanos. España, por su parte, difunde su cultura intelectual en Universidades y Estudios. Las dos razas y las dos culturas se compenetran poco a poco. Es verdad que a los principios de la evangelización se destruyen monumeritos y códices indigenas para ahuyentar todo peligro de reincidencia en el paganismo a los nuevos cristianos. Pero, pasados estos primeros fervores de destrucción, se nota un esfuerzo en los cronistas por conservar la tradición y cultura indígenas. Aun con las salvedades que les imponía su fe y celo de misioneros, hay que admirar en los escritos de Motolinia, de Sahagún, de Vasco de Quiroga, la transmisión, cariñosa y admiradora a veces, de las instituciones culturales de los antiguos mexicanos. A esta difusión de la cultura mexicana contribuyeron no poco varios mestizos ilustres. Recuérdese, por ejemplo, aquella admirable Relación de Texcoco, de Juan Bautista de Pomar, hijo de español y nieto del rey Netzahualpitzintli, en cuyas primeras páginas encontramos un lamento por haberse perdido muchas 
fuentes documentales antiguas. "Esta relación --dice- 8 se hizo con la verdad posible y habiendo primero hecho muchas diligencias para ello buscando indios viejos y antiguos inteligentes de lo que en la dicha institución se contiene, buscando cantares antiquísimos de donde se coligió y tomó lo más que se ha hecho y escrito; y si en el discurso no se desmenuza y especifica lo que significaban algunas cosas de sus dioses y ídolos y ceremonias, antigüedades y costumbres, no se atribuya a descuido y negligencia, sino a que no se ha podido saber más, porque aun cuando hay indios viejos de a más de ochenta años de edad, no saben generalmente todas sus antigüedades, sino unos uno, y otros otro; y los que sabían las cosas más importantes, que eran los sacerdotes de los ídolos, y los hijos de Netzahualpiltzintli, rey que fué desta ciudad y su provincia son ya muertos; y demás desto faltan sus pinturas en que tenían sus historias, porque al tiempo que el Marqués del Valle D. Hernando Cortés con los demás conquistadores entraron la primera vez en ella... se las quemaron en las casas reales... en un aposento que era el archivo general de sus papeles en que estaban pintadas todas sus cosas antiguas, que hoy día lloran sus descendientes con mucho sentimiento, por haber quedado como a escuras sin noticia ni memoria de los hechos de sus pasados; y los que habían quedado en poder de algunos principales... los quemaron de temor de D. Fr. Juan Zumárraga primer Arzobispo de México, porque no los atribuyese a cosas de idolatría."

México deja su huella también en los espíritus clásicos y renacentistas que venían a enseñar en su Universidad. Francisco Cervantes de Salazar se ve compulsado a dejar testimonio de esta influencia en sus Diálogos Latinos (1554), en los que exalta a México y a su Universidad, describe las bellezas de strs calles, plazas y mercados, alaba su clima y sus productos, y la considera superior en muchas cosas a España. 9 "Considera dicho de la Nueva España, nos dice en su diálogo tercero, lo que Cicerón escribió del Asia, pues como él dijo, aventaja sin disputa a todas las naciones del mundo en la fertilidad de su suelo, en la variedad de sus productos, en la extensión de sus pastos, y en el gran número de géneros de contratación: digna, en fin, de que por la admirable templanza del clima se le llame también la Afortunada, como a las islas de este nombre; pues aunque en partes es algo caliente, y en otras algo fría, nunca excede de límites moderados. Es tal la temperatura de México y de los lu- 
gares vecinos, que así en invierno como en verano puede usarse la misma ropa en la persona y en la cama. .. . Críanse en toda la Nueva España caballos excelentes, de admirable agilidad, y que casi nunca se cansan de correr o andar: son, en suma, más hermosos que los de España."

Pero el español mexicano que más sintió al aliento de México fué Bernardo de Balbuena, que "si no nació en la Nueva España, fué el primer escritor que acertó a dar el carácter propio de esta parte de América a su obra descriptiva". $10 \mathrm{Su}$ poema Grandeza Mexicana (1604) canta, como nos dice él, 11 "Las grandezas y admirables partes de esta insigne ciudad de México, a quien por mil nobles respetos he sido siempre aficionado y debía hacer algún servicio." Es digna de memoria su admiración por México expresada noblemente en la Egloga sexta de su Siglo de Oro: "Mas luego que sentada encima de sus delicadas ondas vi una soberbia y populosa ciudad, no sin mucha admiración dije en mi pensamiento: ésta es sin duda aquella Grandeza Mexicana, de quien tantos milagros cuenta el mundo. $\mathrm{Y}$ bien que ya otras veces oyese decir que sobre collados de agua tenía el fundamento, no por eso creía que así toda pendiente en el aire sobre tan delicado suelo estribase; el cual no otra cosa me parecía mirándolo encima de mis hombros, que aquella delicada costra en que labrando las industriosas abejas sus panales suelen también edificar torreados y hermosos castillos de limpia cera; por cuya causa con un nuevo y particular gusto despacio me puse a contemplar semejantes maravillas, llevando a veces la vista por las anchas y hermosas calles cargadas de soberbios edificios, a veces contemplando sus ilustres ciudadanos, sus galanes y ataviados mancebos, como unos valientes y poderosos centauros sobre lozanos y revueltos caballos cubiertos de guarniciones y jaeces de oro, sus hermosísimas y gallardas damas, discretas y cortesanas entre todas las del mundo; los delicados ingenios de su florida juventud ocupados en tanta diversidad de loables estudios, donde sobre todo la divina alteza de la poesía más que en otra parte resplandece." 12

Balbuena, a quien Menéndez y Pelayo 13 ha 1lamado "el verdadero patriarca de la poesía americana y, a despecho de los necios pedantes de otros tiempos, uno de los grandes poetas castellanos", termina su poema pasando de la grandeza de México a la grandeza de España. Los dos países están entrelazados en su alma. En él, 
como en Alarcón, en Sor Juana Inés de la Cruz y en Carlos de Sigüenza y Góngora, el mexicanismo es algo latente y vivo, pero inseparable de lo español.

$Y$ no podía ser de otra manera. El poderío de España, la supremacía de su espíritu, se cernían sobre México, y los españoles mexicanos se veían herederos de su grandeza. Lo notable es que a la par de esta solidaridad con la patria grande crezca también el sentimiento de la nacionalidad nueva, que modifica la heredada tradición española con la levadura de elementos propiamente indígenas. El barroquismo en arte con motivos y salpicaduras del nuevo mundo, el pomposo ornato en las formas literarias, las notas extremadas de cortesía, fiestas y modas en la sociedad virreinal, son manifestaciones paralelas de esta nuteva alma que surgía en México.

Para el mexicano del siglo XVII España es la mađre común que comparte con otros pueblos americanos, pero en México, su patria propia y exclusiva, cifra su orgullo y su nobleza. Sigüenza y Góngora, en su "Relación" sobre el alboroto y motín de 1692, nos dice: 14 "No soy tan amante de mi patria, ni tan simple, que me persuada a que cuanto hay y se ejecuta en ella es absolutamente lo mejor del mundo; pero aunque no he salido a peregrinar a otras tierras (harto me pesa), por lo en extremo mucho que he leído, paréceme puedo hacer concepto de lo que son y de lo que en ellas se hace. Con este presupuesto, le aseguro a Vd. con toda verdad, no haber tenido que envidiar México a otro cualquiera lugar que no fuere esa corte de Madrid." Conocedor y estimador de la historia y cultura del México precortesiano, fué probablemente la mayor autoridad de su tiempo en estas materias. Como nos dice su biógrafo Irving A. Leonard, 15 Sigüenza "llegó a estar versado en las lenguas de los aborígenes e hizo profundo estudio de las antigüedades de los indios, algunas de las cuales coleccionó por sí mismo y otras logró obtener del erudito indio Fernando de Alva 'Ixtlilxóchitl, descendiente de los antiguos reyes de Texcoco. Como resultado de sus investigaciones arqueológicas, Sigüenza se comprometió a escribir una historia completa del imperio de los Chichimecas, procurando trazar sus migraciones y su desarrollo. Aprovechó sus grandes conocimientos astronómicos para interpretar las fechas de los sucesos de los indios, que descifró de sus monumentos, de acuerdo con el calendario cristiano." 
$\mathrm{Su}$ amor a todo lo genuinamente mexicano no le permite perder ocasión de rendir tributo a la excelencia de sus compatriotas. Hablando en su Triunfo Parténico, 16 por ejemplo, de las pinturas que adornaban la Academia Mexicana en cierta fiesta, dice que "eran éstas no sólo de extrangeros pinceles, por quien tendrán prolija vida los coloridos, sino también de nuestros mexicanos compatriotas que merecen el ladeárseles como iguales; poco es esto, el colocarse en más supremo lugar como superiores, y no solo respecto de aquellos, sino aún de los Zeuxis, Apeles, Parrhasios y Timantes."

A pesar de su lealtad indiscutible a la patria grande, parece a veces demostrar cierto despego hacia los españoles de la península. En la "Relación" citada, hablando de cierta enfermedad del trigo, dice que es el chiahuixtle, "que, si es lo que allá llaman los labradores pulgón, lo que según el vocabulario mexicano le corresponde a esta voz, bien puede discurrir Vd. lo que será chiahuixtle". 17 Más adelante, describiendo la plebe que inịció el alboroto, le llama "la más infame de todas las plebes, por componerse de indios, de negros, criollos y bozales, de diferentes naciones, de chinos, de mulatos, de moriscos, de mestizos, de zambaigos, de lobos y también de españoles, que en declarándose zaramullos (que es lo mismo que pícaros, chulos y arrebatacapas) y degenerando de sus obligaciones son los peores entre tanta canalla." 18

Leyendo cuidadosamente esta pintoresca y detallada relación del famoso alboroto ocasionado por la carestía del maíz y del trigo, es difícil averiguar si Sigüenza pone a los españoles fuera del grupo mexicano o si los considera parte integral de él. Por una parte, cuando menciona a los españoles, contra quienes iba el alboroto, parece incluir entre ellos a los criollos que, como él, no conocían otra patria que México. Tratando de explicar el significado de cierto "número de muñecos o figurillas de barro (hallados en la acequia nueva) y de españoles todas, y todas atraviesadas con cuchillos y lanzas que formaron del mismo barro, o con señales de sangre en los cuellos como degollados" dice que era "prueba real de lo que en extremo nos aborrecen los indios y muestra de lo que desean con ansia a los españoles, porque como en aquel lugar fué desbaratado el Marqués del Valle cuando en la noche del 10 de julio de mil quinientos y veinte se salió de México, y según consta de sus historias, se lo dedicaron a su mayor dios (que es el de las guerras) como ominoso para nosotros y para ellos feliz." 19 Por otra parte, a lo 
largo de la "Relación" se vislumbra una nota de extrañeza para el español no identificado con México. Dice Sigüenza: "No les pareció a los indios... que quedaban bien si no entraban a la parte en tan considerable despojo, y mancomunándose con aquellos y con unos y otros cuantos mulatos, negros, chinos, mestizos, lobos y vilísimos españoles, así gachupines como criollos (que) allí se hallaban, cayeron de golpe sobre los cajones donde había hicrro y lo que dél se hace, así para tener hachas y barretas para romper los restantes como para armarse de cuchillos que no tenían." $\mathrm{Y}$ más adelante: "al mismo tiempo que los españoles que estaban en las bocas de las calles en el Cementerio de la Catedral y en otras partes, los reconocieron, se fueron interpolando con los tumultuantes y como éstos, cargados de mercadurías y de riqueza no sólo se iban saliendo de la Plaza atropelladamente, sino que se mofaban con mucha risa de los que entraban y les decían: ¡Españoles de porquería, ya vino la flota! Andad, mariquitas, a los cajones a comprar cintas y cabelleras"... "arrepentidos éstos de haberse estado mirando mano sobre mano tanto destrozo, o avergonzados de oír estas ignominias y otras peores, y sobre todo, con el seguro de que ya no había pedradas, unos con carabinas y con espadas otros dieron con ellos". 20

A la vista de estos textos, no es difícil suponer que en la mente de Sigüenza la idea de nacionalidad mexicana era tan compleja o confusa como la turba de diferentes razas que él mismo menciona. Esta complejidad tenía en su capa inferior al indio, al que había que asimilar, gobernar y educar, en su centro al criollo y al mestizo (que era el verdadero nuevo mexicano), y en su parte superiot al español gachupín o peninsular.

La raza española y la mexicana, en su proceso de asimilación y fusión, estuvieron, pues, en continua lucha. La lucha existía más o menos declaradamente, no sólo en la vida diaria sino también en la vida del espíritu, interno y callado; y al llegar al siglo XVIII de esta lucha silenciosa de dos siglos se forma y va apareciendo poco a poco el alma nacional mexicana, típica y distinta, condicionada por la geografía (belleza y grandiosidad del paisaje), por la historia (restauración del interés en las culturas precortesianas) y por el desarrollo peculiar que en México adquieren la cultura y arte españoles (barroquismo, ornato extraordinario en las manifestaciones literarias y artísticas, cortesía y caballerosidad extremadas). 
A fines del siglo XVIII vemos ya la cristalización de esta nueva alma nacional que adquiere conciencia intensa de sí misma. $Y$ su testimonio más claro lo encontramos en los humanistas mexicanos. Este grupo, formado principalmente por ilustres jesuitas que, desterrados de su patria, dan al mundo un sinfín de obras ensalzando las glorias y la cultura de su añorado México, es para mí el más significativo y quizás el más brillante de las letras mexicanas. De ellos ha dicho con razón un crítico que "maduraron su cultura auténtica y visceralmente mexicana e hicieron irradiar sobre el mundo el esplendor del humanismo criollo". 21

Estos jesuítas que habían dedicado la mayor parte de su vida a los estudios humanistas y a la educación de la juventud, y se vieron trasladados a Italia al ser suprimida la Compañía de Jesús, iluminan todo un siglo, que como ha dicho Henríquez Ureña, 22 "es acaso el siglo de mayor esplendor intelectual autóctono que ha tenido México". Lástima grande fué que las circunstancias del destierro les obligaran a publicar la mayor parte de sus obras en latín o en italiano. Pero, aun así, y quizás por ello, propagaron con éxito en Europa el evangelio de la nueva nacionalidad mexicana, y su mensaje se halla esparcido en varias lenguas en páginas brillantes sobre teología, filosofía, historia, arqueología y las bellas artes.

En todas estas obras, desde la Rusticatio Mexicana de Landívar hasta las biografías de mexicanos ilustres de Maneiro, se nota intensamente el vivo amor a la patria lejana, patria que ya no parece ser un apéndice de España, sino un hogar propio y exclusivo de todos los que en México nacieron y se criaron. Por esta patria suspira Juan Luis Maneiro, cuando en una de sus poesías nos dice: 23

Tiene la patria no sé qué dulzura que siempre gira el corazón por ella sin hallar otro bien en su amargura ni en sus viajes ideales otra estrella.

Pide también al rey de España que al menos se le permita volver a morir en México:

Sepultura, señor, en patrio suelo pedimos a tu trono soberano; quisiéramos morir bajo aquel cielo que influyó tanto a nuestro ser humano. 
En medio de las bellezas y maravillas de la ciudad eterna, el mexicano desterrado piensa con cariño y nostalgia en su bello México, y dice a su hermana que se quejaba de la fealdad de Tacuba:

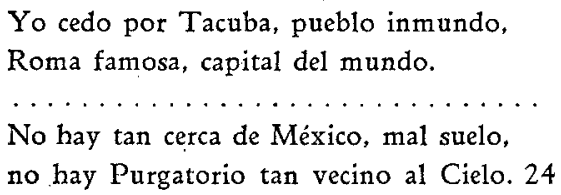

Estos humanistas, como dice Méndez Plancarte, "no se sienten ya españoles sino mexicanos, y así lo proclaman con noble orgullo en la portada de sus obras; abogan por el mestizaje entre españoles e indígenas como medio de lograr la fusión no sólo física sino espiritual de ambas razas y de forjar una sola nación; tienen ya conciencia - profética- de la patria inminente que está gestándose en la Nueva España". Su actitud frente al régimen colonial es, desde luego, actitud de despego y casi diríamos de "extrañeza": hablan de "los españoles" como quien habla de extranjeros, no de compatriotas. Pero tampoco se sienten indios ni sueñan con un imposible retorno al imperio azteca. No son españoles; no son aztecas: ¿qué son, entonces, y cuál es su patria? Son, y quieren ser, "mexicanos".

Este amor a México y esta conciencia de nacionalidad que ahora aparece ya disgregada de la española hacen que estos humanistas vindiquen en sus escritos los valores culturales precortesianos e incrementen la estima de los valores indígenas, ya iniciada en el tiempo de Sigüenza y Góngora. Así Clavijero, en su Storia Antica del Messico 25 estudia la nobleza de carácter de los antiguos mexicanos, su educación y virtudes cívicas, las bellezas de su lengua y de su poesía y lo extraordinario de su pintura, escultura y arquitectura. $\mathrm{Su}$ ideal nacional era una fusión completa y absoluta de las razas española y mexicana y lamenta que los españoles no hubieran adoptado el mestizaje como regla desde el principio de la conquista.

"Conserváronse - dice- 26 hasta la ruina del Imperio con grande esplendor muchas familias descendientes de aquellos ilustres aztecas fundadores de México, y aun ahora existen ramas de aquellas casas antiquísimas, aunque enriquecidas por la miseria y confundidas por la plebe más oscura. No hay duda que hubiera sido 
más sabia la política de los españoles, si en vez de conducir a México mujeres de Europa y esclavos de Africa, se hubiesen empeñado en formar de ellos mismos y de los mexicanos, una sola nación, por medio de enlaces matrimoniales. Si la naturaleza de esta obra to permitiera, haría aquí una demostración de las ventajas que de aquella medida se hubieran seguido a las dos naciones, y de los perjuicios que del sistema opuesto han resultado."

Andrés Cavo, en Los tres siglos de México, 27 obra que dice haber escrito "por el amor de la patria y para servir a su nación", continúa la empresa de Clavijero. En marco heroico coloca al rey Cuauhtémoc, cuya muerte considera "uno de los hechos más bárbaros de la historia". Defiende la libertad de los indios y, haciéndose eco del P. Las Casas, lamenta el "yugo de los españoles". Como Clavijero, Cavo ve la necesidad y la sabiduría del mestizaje para la unidad nacional y añade que "si desde la conquista los matrimonios hubieran sido promiscuos entre ambas naciones, con gran gusto de los mexicanos en el discurso de algunos años, de ambas se hubiera formado una sola nación, y tantas ciudades florecientes que en tiempo de aquellos reyes estaban sembradas por aquellas vastas regiones, se conservarían intactas, y lo que es más, los españoles no serían malquistos de los naturales, cosa aún en nuestros días la más lamentable y que tiene unas consecuencias funestísimas."

No menos consciente de esta patria que aparece en el siglo XVIII es Pedro José Márquez, quien en su obra Due antichi monumenti 28 ensalza la cultura de los antiguos mexicanos, excusa y racionaliza la práctica de los sacrificios humanos, pues "casi no ha habido nación alguna en el mundo que en algún tiempo no haya usado semejantes sacrificios", y establece un paralelo entre Grecia y México. Márquez, profundo esteta, cuyo discurso sobre la belleza es uno de los más luminosos de su tiempo, siente también la ternura de la patria lejana y dedica su obra a la ciudad de México, "donde floreció antaño la singular cultura de sus primeros fundadores, y donde ahora florecen las letras y toda suerte de erudición europea", terminando su oferta con estas palabras: "acoged, benignos, esta pequeña obrilla que desde la lejana Italia os ofrece quien protesta haber sido $\mathrm{y}$ ser todavía amante $\mathrm{y}$ obsequiosisimo hijo $\mathrm{y}$ servidor de la común patria." 29

La nota idílica nos la da Rafael Landívar. En los sonoros hexámetros de su Rusticatio Mexicana 30 canta las bellezas de los mon- 
tes, de los lagos, de los pueblos mexicanos, a la vez que describe con toques realistas las chinampas de Xochimilco, las fiestas populares, los pájaros y los productos tropicales.

Estos testimonios de nacionalidad bien definida no son únicamente el producto de una añoranza por el terruño lejano. Muchas de las obras de estos preclaros jesuítas habían sido escritas o concebidas en México, antes de salir ellos al destierro. Son el producto de una gestación larga de generaciones criollas y mestizas, el fruto de dos culturas después de dos siglos de compenetración. Seguramente que los sentimientos manifestados en ellas eran compartidos por infinidad de mexicanos que con ellos se habían educado. E1 destierro y la nostalgia de la patria sólo fueron la causa inmediata del énfasis y de la frecuencia con que estos sentimientos se repetían. Pero este énfasis y esta frecuencia nos demuestran que el mexicano del siglo XVIII era ya distinto del mexicano del siglo XVII. Y si en México mismo no encontramos documentos literarios tan fehacientes de la nueva nacionalidad en oposición a la antigua española (si exceptuamos a Lizardi, que escribe ya en los días de la lucha por la independencia), lo deberemos atribuir a sabia prudencia ante la sensibilidad del gobierno virreinal y de las clases gobernantes españolas.

Con la aparición de la idea de nacionalidad, establecida ya a fines del siglo XVIII, se preparaba el terreno para el resurgimiento de la nación política. Cuando México lucha y obtiene su independencia de España, se realiza en el plano político lo que ya existía ent el plano espiritual y consciente de la personalidad mexicana. México era independiente de España, en cuanto al alma, mucho antes de la fecha de su independencia política en el siglo XIX.

$$
\begin{gathered}
\text { Hermenegildo Corbató, } \\
\text { University of California, } \\
\text { Los Angeles. }
\end{gathered}
$$

\section{NOTAS}

1 Crónicas de la Conquista de México, Introducción de Agustín Yáñez. (México, 1939), p. 1.

2 S. de Madariaga, Hernán Cortés (Buenos Aires, 1941), p. 276. 
3 Bernal Díaz del Castillo, Historia Verdadera de la Conquista de la Nueva España (Madrid, 1933), I, cap. LXXVII, p. 250.

4 Cartas y Relaciones de Hernán Cortés. . colegidas e ilustradas por D. Pascual de Gayangos (París, 1886), p. 322.

5 Agustín Yáñez, Fray Bartolomé de las Casas (México. 1942), pp. 50-51. Véase también su Introducción a Bartolomé de las Casas. Doctrina (México, 1941).

6 "Información en Derecho", en Don Vasco de Quiroga-Documentos. Introducción y notas por Rafael Aguayo Spencer (México, 1939), p. 381.

7 Ibid., p. 386.

8 Juan Bautista de Pomar, Relación de Tezcoco, en "Nueva Colección de Documentos para la Historia de México" (México, Edit. Salvador Chávez Hayhoe, s. a.), p. 3. Esta obra es una reproducción reciente de obras editadas por don Joaquín García Icazbalceta en 1891.

9 Francisco Cervantes de Salazar, México en 1554 (Edic. de la Uniy. Nac. Aut., México, 1939), pp. 144-145.

10 Bernardo de Balbuena, Grandeza Mexicana. Edic. y prólogo de Francisco Monterde (México, 1941), p. xi.

11 Francisco Monterde, en su Introducción a la obra citada de Balbuena, p. ix.

12 Citado por Monterde, ibid., pp. xi-xii.

13 Ibid., p. xviii.

14 Carlos de Sigüenza y Góngora, Relaciones Históricas. Selección, prólogo y notas de Manuel Romero de Terreros (México, 1940), p. 104.

15 Citado por Romero de Terreros, op. cit., p. xiii. Véase también I. A. Leonard, Don Carlos de Sigüenza y Góngora (Berkeley, 1929), cap. vi, pp. 90-102. xiv.

16 Sigüenza y Góngora, Relaciones Históricas (México, 1940), p.

17 Ibid., p. 119.

18 Ibid., p. 128.

19 Ibid., p. 134.

20 Ibid., pp. 15s-156.

21 Gabriel Méndez Plancarte, en su Introducción a Humanistas del siglo XVIII (México, 1941), p. x.

22 P. Henríquez Ureña, Antología del Centenario (México, 1910), II, p. 661.

23 Estas y otras poesias, citadas por Méndez Plancarte en su Introducción a Humanistas del siglo XVIII, fueron recogidas de un manus-. crito de la Biblioteca Nacional de México. Op. cit., pp. xi-xii y nota 6, 'p. $\mathrm{xxy}$.

24 Ibid., p. xi. 
25 Historia antigua de México... por el Abate Francisco Javier Clavijero. Traducida del italiano por J. Joaquín Mora (México, 1917). Se hallan extractos importantes en la obra de Méndez Plancarte, antes citada.

26 Méndez Plancarte, op. cit., p. 37.

27 Ibid., pp. 83-111.

28 Extractada en el citado libro de Méndez Plancarte, pp. 129-160.

29 Ibid., p. 131.

30 Raphaelis Landivar Rusticatio Mexicana (Bolonia, 1782). 